\title{
Minor Pathologic Response
}

National Cancer Institute

\section{Source}

National Cancer Institute. Minor Pathologic Response. NCI Thesaurus. Code C123592.

A minor decrease in signs of cancer, supported by pathological examination and based on pre-defined thresholds. 